\title{
MIDAS
}

Museus e estudos interdisciplinares

$8 \mid 2017$

Dossier temático "Objetos e museus: biografias, narrativas e vínculos identitários"

\section{Por detrás de uma coleção do Museu Nacional do Rio de Janeiro: vozes, silêncios e desafios}

Behind a collection in the National Museum of Rio de Janeiro: voices, silences and challenges

\section{Cecilia de Oliveira Ewbank e Manuel Ferreira Lima Filho}

\section{OpenEdition \\ Journals}

\section{Edição electrónica}

URL: http://journals.openedition.org/midas/1233

DOI: $10.4000 /$ midas. 1233

ISSN: 2182-9543

Editora:

Alice Semedo, Paulo Simões Rodrigues, Pedro Casaleiro, Raquel Henriques da Silva, Ana Carvalho

\section{Refêrencia eletrónica}

Cecilia de Oliveira Ewbank e Manuel Ferreira Lima Filho, « Por detrás de uma coleção do Museu Nacional do Rio de Janeiro: vozes, silêncios e desafios », MIDAS [Online], 8 | 2017, posto online no dia 31 julho 2017, consultado no dia 20 abril 2019. URL : http://journals.openedition.org/midas/1233 ;

DOI : 10.4000/midas. 1233

Este documento foi criado de forma automática no dia 20 Abril 2019

\section{cc) (†) (2)}

Midas is licensed under a Creative Commons Attribution-NonCommercial-ShareAlike 3.0 International License 


\section{Por detrás de uma coleção do Museu Nacional do Rio de Janeiro: vozes, silêncios e desafios}

Behind a collection in the National Museum of Rio de Janeiro: voices, silences and challenges

Cecilia de Oliveira Ewbank e Manuel Ferreira Lima Filho

\section{NOTA DO EDITOR}

Artigo recebido a 31.03.2017

Aprovado para publicação a 24.07.2017

\section{Introdução}

1 Fundado em 1818, o Museu Nacional (MN) do Rio de Janeiro (Universidade Federal do Rio de Janeiro) insere-se no conjunto dos espaços institucionais em que se desenvolveu uma tradição de pesquisa científica no Brasil. Criado por D. João VI para abrigar as coleções de espécimes e artefatos reunidos pela casa imperial portuguesa, em 2007 o seu acervo já ultrapassava os 15 milhões de objetos (Museu Nacional 2007). Atuando em conformidade com a especialização das ciências definida ao longo dos séculos, a pesquisa antropológica no MN encontra-se hoje organizada no Departamento de Antropologia cujo setor de Etnologia e Etnografia (SEE) detém um acervo composto de aproximadamente $42 \mathrm{mil}$ objetos, dos quais 30 mil se relacionam com grupos indígenas brasileiros, sendo uma pequena parte referente à coleção de William Lipkind.

Incorporada no MN no final da década de 1930, a sua musealização inclui a atual pesquisa no âmbito do projeto Kanaxywe ${ }^{1}$. Iniciado em 2014 sob a coordenação de Manuel Ferreira 
Lima Filho (Universidade Federal de Goiás), o projeto Kanaxywe teve por objetivo primeiro $^{2}$ a identificação e a localização, na reserva técnica do SEE/MN dos objetos reunidos por W. Lipkind aquando da sua pesquisa de campo entre os Karajá3 (1938-1939). Esta etapa inicial serviu de base ao desenvolvimento de outras etapas, cujo objetivo final consistiu na devolução simbólica da coleção e do seu uso patrimonial e educacional aos Karajá a partir de uma visita à reserva técnica, ativando o potencial dialógico do museu. 0 registro da frequência de determinadas tipologias de objetos e de etnias, somadas à trajetória profissional de W. Lipkind e, institucional da coleção, possibilitam algumas reflexões acerca da construção e da circulação da coleção no âmbito museológico e antropológico.

3 Na prática investigativa, Rússio (1990) atenta que o direcionamento da pergunta ao facto museal $^{4}$ tem como parâmetros os princípios da documentalidade, testemunhalidade e fidelidade, aspetos que incidem sobre:

[...] a busca, organização e sistematização das fontes geradoras dos fatos e seus testemunhos materiais, até a veracidade dos documentos e o compromisso com a possibilidade de expansão do conhecimento derivado de pesquisa junto às fontes.

(Rússio cit. por São Paulo 2010, 30)

4 A fim de questionar as inflexões que esta vivência no MN ensejou sobre a biografia da coleção etnográfica constituída por W. Lipkind, tomámos como campo de pesquisa o arquivo, enquanto espaço «povoado por sujeitos, práticas e relações suscetíveis à análise e à experimentação antropológica» (Cunha e Castro 2005, 4), e compreendendo como extensão do seu corpus documental, os registros catalográficos aos quais os objetos são submetidos no museu enquanto «fontes geradoras dos fatos», como colocou Bottallo (1996).

\section{Problematizando a coleção}

5 Mediadoras do visível e do invisível, as coleções museológicas dialogam com os espectadores, mas também com os contextos históricos e sociais em que foram formadas e o controle de significados que reverberam (Pomian 1984; Gonçalves 2007; Price 2007) encerrando na sua genealogia atributos históricos, geográficos, sociais e estéticos, mas também simbólicos, oriundos das experiências de compartilhamento nos ecossistemas que integram. Appadurai argumenta que «embora de um ponto de vista teórico atores humanos codifiquem as coisas por meio de significações, de um ponto de vista metodológico são as coisas em movimento que elucidam seu contexto humano e social» $(2008,17)$. Os sentidos e imagens emanadas destas relações circulam de forma contínua e dinâmica, antecedendo a sua materialização no mundo e a sua integração na coleção (Silveira e Lima Filho 2005). Disto decorre que a apreensão dos objetos reunidos por W. Lipkind na década atual reclama uma perceção mais atualizada sobre o papel do museu enquanto regulador dos atributos e sentidos imanentes à coleção, apontando os silêncios que a envolvem (Truillot 1995; Lima Filho 2010; Price 2016), mas também como propulsor da potência das coisas a partir de uma participação compartilhada e colaborativa.

6 Salvaguardadas nas reservas técnicas dos museus, as coisas oscilam nos seus significados. Atribuir uma linearidade a um conjunto de objetos como forma de definir uma coleção não é uma tarefa fácil, como já se questionava Pomian: «Mas como se pode então caracterizar, em geral, e sem ceder às tentações do inventário, este universo composto de 
elementos tão numerosos e heteróclitos? O que tem de comum uns com os outros?» (Pomian 1984, 51). Na prática museológica,

[...] o que permite a contextualização ou conexão dos objetos de um museu entre si é a organização em coleções, que são conjuntos geralmente constituídos artificialmente, de acordo com a temática, a função ou outros aspetos comuns dos objetos. (São Paulo 2010, 32)

7 No SEE/MN adotou-se o sistema de um único número, sucessivo e sequencial para a inscrição dos objetos no Livro de Registros. No seu estudo sobre a coleção de indústria humana do MN, Nascimento $(2009,33)$ identificou que o uso desta metodologia remonta à primeira listagem feita das coleções etnográficas do museu, por ocasião da publicação dos relatórios e guias da Exposição Antropológica, em 1882. O índice remissivo da coleção institucional do MN, a referência aos doadores, coletores e colecionadores surge aqui como uma informação secundária reservada a identificar o material externo ao museu, incorrendo na diluição das características específicas em prol do registro do conjunto único, conquanto diverso. É neste sentido que Nascimento sugere a discriminação em "coleção etnográfica", compreendida enquanto «um conjunto de coleções preparadas para o futuro. Não só através de um colecionador, que claramente pensa em algo a ser preservado e observado no futuro, mas através de pessoas que, em determinado momento, exerceram funções institucionais» (Nascimento 2009, 33-34), atentando para as ressignificações a que um objeto está sujeito no trânsito específico entre a sua coleta e a transposição para uma instituição pública ou particular (Velthem 2012).

No caso do museu, a perda do caráter utilitário do objeto propicia a confrontação com a coisidade do objeto (Brown 2001, 4). Por fim, considerando-o ainda um espaço composto de coleções, acatamos a sugestão de Semedo, de que «todas as outras funções museológicas geralmente apreciadas não podem ser conseguidas sem primeiro considerar as coleções; quer dizer, sem primeiro considerar o recurso primário de um museu a partir do qual qualquer outra função se desenvolve» (Semedo 2005, 310). Dessa forma, o enquadramento do conjunto sob a denominação coleção etnográfica W. Lipkind procurou reiterar a identidade histórica, os vínculos e os silenciamentos que delineiam a biografia dos objetos.

Suprimida da bibliografia relacionada com os Karajá ${ }^{5}$, as interferências inerentes à sua incorporação no MN incorrem em ausências, algumas delas passíveis de observação na documentação referente ao seu registro. Inscritos nos Livros de Registro do SEE através do número de identificação e complementado por outras informações básicas, 527 itens acusaram o nome de W. Lipkind e a data de coleta/recolha/registro: março de 1939. Majoritariamente composto por objetos de procedência Karajá, mas também Javaé, Gorotire, a coleção foi dispersa entre os Livros de n. 15 (28.611-28.752), 17 (30. 684-30.921) e 19 (36.541-36.688; 36.691). ${ }^{6}$

10 Na sua análise sobre a catalogação das coleções etnográficas do SEE, Nascimento afirma que os «registros posteriores de peças antigas à medida que eram "encontradas" são observados como sendo um procedimento comum, uma vez que a falta de espaço e o excesso de material, são queixas comuns ao longo dos 189 anos de existência da instituição» (Nascimento 2009, 41), metodologia que ocasionou a perda de informações relevantes como a data de incorporação e o nome do coletor. As datas de coleta/recolha/ doação dos objetos que antecedem a inscrição da coleção etnográfica W. Lipkind nos três Livros de Registro, a saber 1939 (28.610), 1940 (30.683) e 1953 (36.540), confirmam a 
hipótese do registro posterior e sugerem que a sua catalogação ocorreu próxima a estas três datas. ${ }^{7}$

11 Por outro lado, o alerta de Canclini sobre os processos de hibridação (2003), ou seja, descrições generalizadoras que dissolvem as características específicas dos objetos, além de omitir qualquer menção ao contexto colonial em que foram produzidas estas coleções, reclama a atenção para os procedimentos empregues na formação da coleção para não esvaziar da análise a perspetiva colonialista (Thomas 1991) daí a necessidade de recontextualizá-las (Velthem 2012). Afinal, se a data de coleta/recolha/incorporação é comum a todos os itens desta coleção, quais as contingências que ocasionaram o seu registro em três tempos distintos? Uma vez divididos, quais os fatores que intercederam para resultar numa diferença menor no intervalo numérico entre os dois primeiros registros, comparado com o último? Considerando as relações que a documentação museológica mantém com o histórico de cada objeto, e de cada unidade entre si, com as demais coleções e com a história do próprio museu (São Paulo 2010, 51).

o presente artigo baseou-se na pesquisa realizada pelos autores no conjunto de documentos museológicos do SEE/MN e complementada através da consulta aos arquivos, a fim de refletir sobre a biografia da constituição e registro da coleção etnográfica W. Lipkind do SEE/MN, confrontando os processos e as narrativas museológicos a partir das questões postuladas acima.

\section{Três tempos para a coleção Lipkind}

Acompanhado da sua esposa, Maria Cimino, e do seu colega na Universidade de Columbia (Estados Unidos), Buell Quain, W. Lipkind veio ao Brasil em 1937 para realizar uma expedição cujos objetivos consistiam na realização de estudos linguísticos e etnográficos, registo fotográfico e coleta de objetos. ${ }^{8} \mathrm{O}$ desenvolvimento da pesquisa de campo entre os Karajá, na região do Araguaia, no Mato Grosso, decorria dos interesses da sua orientadora, Ruth Bennedict, em ampliar as pesquisas sobre os grupos Gê, pouco estudados até então (Benedict 1938). Autorizada mediante o trâmite do processo pela Embaixada Americana, Ministério das Relações Exteriores, Conselho de Fiscalização das Expedições Artísticas e Científicas no Brasil e pelo MN, a licença de pesquisa foi condicionada à entrega de objetos em duplicado para o Governo Brasileiro. 0 estabelecimento deste condicionalismo, bem como a adição de um termo que garantisse a vinda do material para o MN e a prévia autorização por um técnico do Conselho do que poderia ser exportado, só foi possível mediante a influência da antropóloga Heloísa Alberto Torres, à época diretora do MN e sua representante institucional junto do Conselho (Groupioni 1998, 83).

14 À época, o Brasil começava a institucionalizar a proteção do seu património natural, artístico e científico, e o MN era uma das instituições autorizadas para a sua salvaguarda, como deixa entrever Heloísa A. Torres numa carta para o Ministro da Educação, Gustavo Capanema:

Nenhum dos dois [Lipkind e Quain] tem interesse em realizar para si coleções de material etnográfico, mas estão ambos dispostos a fazê-las para o Museu Nacional. A oportunidade de enriquecer o nosso patrimônio me parece ótima bem como seria justo auxiliar de qualquer maneira a esses expedicionários. (Torres 1938, s/p)

15 Se o estudo do comportamento humano, alavancado pela antropologia cultural no período entre as guerras, reduzia o interesse dos seus praticantes pela posse de objetos 
etnográficos para seu próprio estudo (Stocking 1992, 210), o mesmo não ocorria nos museus brasileiros, ávidos, todavia, por ampliar os seus acervos etnográficos.

Composta por uma série de artefactos e registros fonográficos e iconográficos, a primeira parte da coleção reunida por W. Lipkind durante o seu trabalho de campo, em 1938, foi encaminhada para o MN, aos cuidados de Heloísa A. Torres, ainda no final desse ano, para a triagem dos objetos que ficariam no Brasil e daqueles que deveriam seguir para Universidade de Columbia, em Nova Iorque (Wagley 1939, s/p). Numa carta datada de 24 de dezembro de 1938, o antropólogo requisita a pronta remessa para os Estados Unidos da sua parte da coleção - que incluía um cilindro de cera gravado com músicas -, a impressão de todas as fotografias e os negativos fotográficos. W. Lipkind explicava a razão da apressada solicitação: «Eu gostaria de ouvir o Museu Americano antes de voltar a coletar» ${ }^{9} .0$ interesse em obter um parecer da coleção pelos técnicos desse museu incide sobre a avaliação, quer do seu valor museológico enquanto coleção de estudo ou de exibição, quer económico, enquanto parte de um circuito comercial que envolvia antropólogos, museus e colecionadores particulares.

Dividida de forma equitativa em Coleção do Museu e Coleção de W. Lipkind, esta foi despachada em 18 de abril de 1939, conforme certificado do Conselho, referente à exportação para Columbia, de dois caixotes contendo 155 utensílios e adornos de índios. ${ }^{10}$ As «2 caixas com joias indígenas» chegaram em Nova Iorque a 12 de junho de 1939. ${ }^{11}$

18 A presença de informações relativas ao artesão e às características tipológicas dos itens incluídos nas listas acima mencionadas, permitiu verificar a compatibilidade do material destinado à Coleção do Museu com o acervo existente no SEE/MN, contabilizando 140 objetos registados na parte I da coleção. ${ }^{12}$ Assim, quando no dia 8 de março de 1939, Heloísa A. Torres refere que o museu havia já recebido de W. Lipkind «algumas centenas de fotografias e uma valiosa coleção de bonecas dos índios Karajá» ${ }^{13}$, a diretora fazia referência às 12 bonecas ritxoko ${ }^{14}$ indicadas na lista da coleção do museu e que compõem os últimos itens da parte I da coleção etnográfica W. Lipkind. Assim, a remessa para os Estados Unidos parece ser um ponto crucial para compreender a origem da coleção que hoje se encontra no SEE/MN uma vez que o índice cronológico "março de 1939" oficializa a "entrada" dos primeiros objetos da coleção Karajá na instituição, sendo estendido aos demais itens. Contudo, a coleção difere da data de arrolamento das demais coleções nos Livros de Registro, realizadas após agosto de 1939, conforme mencionado anteriormente. O subsequente registro dos objetos coletados por W. Lipkind nos Livros de n.. 17 e n.. 19 remete, portanto, a tempos e circunstâncias distintos de coleta e incorporação da coleção, acusando os desafios de compreender os objetos pelo trabalho que eles performam na sua relação com os sujeitos (Brown 2001).

Analisando a procedência étnica do conjunto total de objetos da coleção etnográfica W. Lipkind, os Karajá1 ${ }^{15}$ são os mais bem representados, com 240 itens, seguidos dos Javaé e dos Gorotire com 134 e 83 itens, respetivamente. ${ }^{16}$ Enquanto os primeiros constam nos três intervalos de registro da coleção, as demais etnias aparecem a partir do segundo registro, na classe dos 30 mil. A incidência das etnias somada a algumas tipologias específicas de objetos a partir do segundo registro, encontra respaldo na documentação referente à montagem de uma segunda coleção pelo antropólogo, a partir de maio de 1939, quando acabara de regressar dos Javaé. 
20 Em carta de 1 de maio de 1939, o antropólogo Charles Wagley, também implicado no acordo informal estabelecido entre a Universidade de Columbia e o MN, escreve para Heloísa A. Torres a respeito da outra coleção que W. Lipkind estava reunindo:

Ele trouxe muitas coisas bonitas (cocares, etc.) e me pergunta se eu acho que você ficaria feliz com essas coisas maravilhosas para o Museu. Respondi por você; a coleção do Museu seria enriquecida com elas. A única coisa que me horrorizou ao fazer essas coleções Karajá é o preço que eles pedem. Vi Lipkind barganhando por coisas feitas para ele e eles queriam materiais que valiam quarenta e cinco mil réis para os cocares - suas razões para tais preços são boas - eles são sagrados, dizem eles. De qualquer modo, Lipkind está juntando uma linda coleção para você e eu espero fazer o mesmo nos Tapirapé. (Corrêa 2008, 143)

No SEE/MN, a continuidade da coleção etnográfica W. Lipkind foi registada em outras duas partes respetivas às classes numéricas dos 30 mil (238 itens) e dos 36 mil (149 itens). No que se refere às tipologias de objetos presentes nestas duas partes, é possível observar que, no geral, apresentam um balanço equitativo; as tipologias que só aparecem numa das partes têm um índice quantitativo geralmente igual a um, e inferior a seis; a diferença $\geq$ que dez itens ocorre em detrimento da classe dos $36 \mathrm{mil}$; as cinco tipologias de objeto cuja diferença é $\geq$ que dez itens se referem a objetos rituais (dois), arqueológicos (um) e de adorno plumário (um). Feitas estas considerações, passamos à apreciação das tipologias de objetos presentes nesta segunda coleção.

Como a publicação da carta já traduzida do inglês para o português em Corrêa (2008) não permite saber qual o termo exato utilizado por Wagley para se referir aos "cocares", consideramos a categoria de adornos plumários de cabeça, usados no crânio (vértex e occipício), definida por Ribeiro (1988) e utilizada na catalogação das coleções etnográficas do SEE/MN. Do total de 41 adornos que compõem a coleção etnográfica W. Lipkind ${ }^{17}$, há sete, de procedência Karajá na parte I, e 34, e um nas partes II e III, respetivamente, de procedência Karajá, Javaé e Gorotire, diferença que sugere uma encomenda de adornos plumários por Heloísa A. Torres na montagem da segunda coleção.

$\mathrm{Na}$ latência amorfa que gera a materialização do objeto por meio da compreensão do sujeito, ou excesso de presença metafísica no objeto (Brown 2001), a menção de Wagley às "coisas" "sagradas" resvala na presença de objetos xamânicos (máscaras e feitiços) na segunda coleção reunida por W. Lipkind. Relacionada com o aprofundamento de W. Lipkind sobre as práticas xamãnicas dos Javaés durante a sua instância no campo quando foi «investido das funções de "Pagé"» ("Pagé dos Javahés" 1939, 4) -, a circulação de determinados objetos da aldeia Karajá para o museu coloca em evidência a dialética da simultaneidade entre coisa e objeto reclamada por Brown (2001). Quando no término da etapa de campo, em setembro de 1939, W. Lipkind avisa Heloísa A. Torres: «Estou trazendo um companheiro Karajá comigo para o Rio. As máscaras de dança tiveram que ser separadas para a embalagem, e ele vai montá-las no museu. Se você pudesse acertar a nossa passagem no Lloyd Brasileiro ou Costeira, seria útil ${ }^{18}$, a necessidade da presença do indígena Karajá no museu parece extrapolar a montagem dos objetos. Se atentarmos para a coisa, ela assegura ao artesão a definição do momento do término e a cessão do objeto marcados não pela assinatura, como colocou De Waal (2012), mas pelo impulso à circulação dos entes no cosmos Karajá, uma vez que este "mundo" não indígena surge como mais um dos lugares possíveis nesse cosmos por onde essas coisas circulam (Andrade 2016). Vinculadas aos rituais festivos e xamânicos dos Karajá, as máscaras de Aruanã presentes na coleção também apresentam uma diferença quantitativa discrepante: 15 itens na ordem dos $30 \mathrm{mil}$, e quatro na dos $36 \mathrm{mil}$. 
comitante à carta de Wagley, W. Lipkind escreveu para Ruth Benedict sobre os fundos financeiros da pesquisa, esclarecendo: «Eu não sei como vai ser para você conseguir oitocentos dólares [...] Talvez você possa conseguir algo com a coleção que Dona Heloísa encaminhou para você» ${ }^{19}$. Num período de escassez de emprego no meio antropológico norte-americano, os objetos assumiam outros valores. Na continuação da carta W. Lipkind tece alguns comentários sobre a conformação tipológica desta coleção que estava organizando e o destino que lhe pretendia dar:

Minhas coleções atuais podem ajudar mais. Eu tenho coisas de aspeto muito melhor, cocares, máscaras, tembetás de cristal. Eu tenho dezesseis tembetás de cristal em perfeitas condições, e um colecionador de São Paulo me ofereceu um conto por peça para tudo que eu conseguisse encontrar. Talvez eles alcancem um valor mais alto em Nova York. Eles são raríssimos e bonitos. Eles são tão bem feitos quanto os machados dos West Indians e a pedra muito mais agradável, uma pedra branca brilhante, quartzo, eu acho. Eu consegui tantos por pura sorte. Eu escavei um antigo cemitério e os encontrei. Mesmo depois de Dona Heloísa fazer seu pior, vai sobrar bastante para conseguir uma parte do dinheiro. ${ }^{20}$

Kopytoff (2008) argumenta que a permanente oscilação de estatuto das coisas ao longo da sua biografia varia de acordo com as classificações individuais ou culturais, tornando-as coisas diferentes em cenários diferentes (Brown 2001). Esta última ideia é elucidativa da relação de W. Lipkind com a coleção e da oscilação do estatuto das coisas. Se o antropólogo não tencionava formar uma coleção para si, como já havia enfatizado Heloísa A. Torres, certamente pretendia angariar fundos com a sua venda. Da mesma forma que a primeira coleção, também esta estava sujeita à partilha conduzida por Heloísa A. Torres por determinação do Conselho, sendo percebida como um empecilho por W. Lipkind, daí que ele se refira claramente ao «depois de Dona Heloisa fazer seu pior». A menção do antropólogo aos tembetás, escavados de um cemitério na antiga aldeia de Fontoura, na ilha do Bananal, e relatado de maneira entusiástica para Ruth Benedict, é importante não só para descortinar a incorporação das duas outras partes da coleção no acervo do MN, mas também para atentar sobre a necessidade de descolonizar os museus em prol do alargamento do facto museal em direção a uma gestão compartilhada, colaborativa e interdisciplinar nos museus (Bruno 2014).

Conforme assinalou De Waal, os objetos também nos impulsionam a procurar o que estes testemunharam na sua vivência no espaço-tempo no intuito de alcançar uma exatidão próxima daquela que denotam materialmente (De Wall 2012). Na coleção etnográfica W. Lipkind do MN, constam 22 tembetás de quartzo procedentes de uma escavação no antigo cemitério da aldeia de Fontoura. Divididos de forma aproximada entre as partes II e III da coleção $0^{21}$ no que se refere à quantidade e ao estado de conservação, daqueles localizados no âmbito do projeto Kanaxywe ${ }^{22} 11$ estão em estado íntegro e nove colados. Se a pesquisa pela biografia do objeto almeja alcançar a mesma exatidão que este denota na sua materialidade (De Waal 2012), há aqui duas constatações a fazer com respeito ao estado de conservação dos objetos. Se, por um lado, a presença no acervo de 11 tembetás dos «dezesseis em condições perfeitas», mencionados por W. Lipkind, é de supor que a maior parte dos tembetás íntegros foi incorporada no instituto. A ausência de informações relacionadas com o estado de conservação dos tembetás nas antigas fichas catalográficas impossibilita o conhecimento das reais condições de conservação dos objetos partidos e colados no momento da sua incorporação na instituição.

Dividida entre o MN e o antropólogo, a segunda parte da coleção destinada ao Instituto foi incorporada por volta de fevereiro de $1940 .{ }^{23} \mathrm{~A}$ hipótese que levantamos é que a parte dos 
objetos destinada à coleção particular de W. Lipkind permaneceu no Brasil, sendo a sua remessa para os Estados Unidos embargada em função do estremecimento da relação com Heloísa A. Torres. Numa carta escrita a Franz Boas, a 2 de janeiro de 1941, em que menciona a coleção, Heloísa A. Torres ressente-se da falta de compromisso de W. Lipkind em enviar o relatório da sua pesquisa, uma das contrapartidas exigidas por ela mediante o Conselho para a autorização da expedição. Neste contexto, refere Heloísa A. Torres:

Eu preciso dizer que eu ajudei o Dr. Lipkind o máximo que pude, mais do que jamais fiz por qualquer dos antropólogos de Columbia; devido às circunstâncias financeiras do momento eu pude ajudá-lo mesmo a este respeito. É verdade que ele deixou uma bela coleção etnográfica dos Karajás para esse museu. Uma atitude diferente da sua parte em relação a outros assuntos era esperada. Eu sinto ter que constatar que a sua própria coleção particular pode ser confiscada pela falta de comprometimento dos requisitos legais mencionados acima. Eu posterguei essa decisão até agora mas, não acredito que possa fazer com que esta situação permaneça por mais tempo. (Torres 1941, s/p) ${ }^{24}$

Pensamos que a coleção particular de W. Lipkind que foi confiscada corresponde à parte III da coleção registada no SEE/MN, na qual constam cinco tembetás de quartzo em estado íntegro e as quatro máscaras. A proporção consideravelmente menor $(\leq 10)$ de máscaras, vasos arqueológicos e braceletes em plumária, e a ausência de feitiços, comparada a parte II, remete aqui à potência que determinados objetos apresentam de organizar os afetos públicos e particulares dos sujeitos (Brown 2001).

Incorporada no MN em 1941, a parte III foi registrada no acervo do museu somente a partir de $1953 .{ }^{25} \mathrm{O}$ porquê do seu registro nesta data parece estar relacionado com o início das obras de consolidação e reparação do edifício do museu em 1941, que incorreram no encerramento do Instituto à visita pública e à reformulação dos espaços e das atividades basilares do museu. Reaberto em 1947 com a inauguração de novas exposições, a parte de antropologia e de arqueologia contou com uma secção dedicada aos grupos Gê, entre os quais os Karajá.

No arquivo do SEE/MN há uma listagem referente à Exposição de Antropologia e Arqueologia onde constam o número de registro dos itens expostos, organizados por sala e vitrine com a respetiva fotografia e identificados por coleção e procedência étnica, sendo a mais recente, a Coleção Esperidião Rocha, de 1957, o que indica a elaboração do documento a partir desse ano. Comparando as fotografias das salas e vitrines presentes na lista, com aquelas publicadas no catálogo da exposição de 1947 (Castro Faria 1949), verificamos que o arranjo dos objetos permaneceu praticamente igual desde a sua inauguração, com a substituição ocasional de alguns objetos.

31 No que se refere aos objetos coletados por W. Lipkind, a sua exposição restringiu-se, basicamente, à primeira e à segunda parte da coleção (classe dos 28 e 30 mil), concentrados na sala XIV, dedicada a diversos aspetos da cultura Karajá, como se pode apreciar na tabela n. $\mathrm{o}$.

Tabela $n .^{\circ} 1$ - Objetos da coleção etnográfica W. Lipkind exibidos na Exposição de Antropologia e Arqueologia do Museu Nacional

\begin{tabular}{|l|l|l|l|l|}
\hline SALA & DENOMINAÇÃO & VITRINE/LOCAL & TIPOLOGIA DO OBJETO & N.ํ DE REGISTRO \\
\hline 12 & $\mathrm{~s} / \mathrm{n}$ & 18 & Flecha & 28.622 \\
\hline
\end{tabular}




\begin{tabular}{|c|c|c|c|c|}
\hline 13 & Objetos de navegação & parede & Remo & 28.684 \\
\hline 14 & Pesca (Karajá) & 6 & $\begin{array}{l}\text { Flecha } \\
\text { Arco } \\
\text { Remo } \\
\text { Clava } \\
\text { Cacete } \\
\text { Lança }\end{array}$ & $\begin{array}{l}30.840 \\
28.621 \\
28.638 \\
30.805 \\
28.690 \\
30.888 \\
28.659 \\
30.800\end{array}$ \\
\hline & Cerâmica (Karajá) & 7 & $\begin{array}{l}\text { Boneca } \\
\text { Machado } \\
\text { Cachimbo } \\
\text { Cabaça }\end{array}$ & $\begin{array}{l}28.741 \\
28.742 \\
28.745 \\
28.748 \\
28.749 \\
30.752 \\
30.719 \\
30.859 \\
30.861 \\
30.878 \\
30.877\end{array}$ \\
\hline & Indumentária & 8 & $\begin{array}{l} \\
\text { Tanga } \\
\text { Pente } \\
\text { Labrete } \\
\text { Abanador } \\
\text { Cinta } \\
\text { Cinto } \\
\text { Pingente } \\
\text { Brinco } \\
\text { Cordel }\end{array}$ & $\begin{array}{l}30.825 \\
30.874 \\
30.875 \\
30.787 \\
30.858 \\
28.652 \\
28.653 \\
28.663 \\
30.892 \\
30.893 \\
30.751 \\
36.630 \\
30.903 \\
30.820 \\
28.670\end{array}$ \\
\hline & Ornamentos (Karajá) & 9 & $\begin{array}{l}\text { Brinco } \\
\text { Diadema } \\
\text { Coifa }\end{array}$ & $\begin{array}{l}30.863 \\
30.749 \\
30.727 \\
30.816\end{array}$ \\
\hline
\end{tabular}




\begin{tabular}{|c|c|c|c|}
\hline Enfeites (Karajá) & 10 & $\begin{array}{l}\text { Ornato de cabeça } \\
\text { Ornato de braço } \\
\text { Capacete } \\
\text { Cinto } \\
\text { Cinta } \\
\text { Diadema }\end{array}$ & $\begin{array}{l}28.675 \\
28.611 \\
30.736 \\
30.828 \\
28.635 \\
30.823 \\
30.730 \\
30.732 \\
30.740\end{array}$ \\
\hline Máscaras de Aruanã & 11 & Máscaras & $\begin{array}{l}30.908 \\
30.909 \\
30.910\end{array}$ \\
\hline Cerimonial & 12 & $\begin{array}{l}\text { Maracás } \\
\text { Pena } \\
\text { Bastão } \\
\text { Máscaras }\end{array}$ & $\begin{array}{l}28.711 \\
28.712 \\
28.713 \\
28.714 \\
30.852 \\
30.853 \\
30.718 \\
30.889 \\
30.920 \\
30.919\end{array}$ \\
\hline
\end{tabular}

Entre as categorias de objetos da coleção adquirida por W. Lipkind e apresentadas na exposição, sobressaem as armas, as cerâmicas, os objetos de indumentária e toucador sobretudo adornos plumários -, e objetos rituais, objetos que, para além do valor material e imaterial que detêm e atribuem, considerando-se o comentário de Wagley sobre as "coisas" "sagradas" organizarem temporalmente o mundo (Brown 2001, 16). Se a existência da vitrine demanda uma escolha e uma apropriação, como assinalou De Waal (2012), esta também precipita a distância e a proximidade que se estabelecem entre objetos e pessoas (Brown 2001, 16), neste caso entre o civilizado e o que ele próprio classifica como primitivo e etnográfico.

A presença massiva de objetos procedentes das partes I e II da coleção Lipkind, incorporadas no acervo do MN em 1939, numa exposição de longa duração sujeita a poucas modificações, com salas dedicadas exclusivamente à cultura Karajá, é possível afirmar que a coleção fez parte do conjunto etnográfico exposto na sua inauguração. Ali estavam as bonecas mencionadas por Heloísa A. Torres e também as máscaras referidas por W. Lipkind, cuja exuberância e representatividade mereceu uma vitrine exclusiva (11), acionando o dispositivo enunciador do museu (Almeida 1996 cit. por Velthem 2012, 55) quanto ao seu papel na salvaguarda do património e na construção da nação. Por outro lado, a ausência de objetos da parte confiscada da coleção (III parte) reforça o 
argumento de que esta permaneceu guardada em depósito sem ser registrada, mesmo após a inauguração da exposição.

\section{Conclusões}

Imerso na reserva técnica, onde existe (e ocupa espaço), o objeto descontextualiza-se. 0 aprofundamento da análise histórica sobre a biografia da coleção etnográfica reunida por W. Lipkind permitiu verificar que os processos de incorporação e registro no MN incorreram na homogeneização das suas etapas formativas, a partir da designação comum da data de incorporação "março de 1939". Procurámos demonstrar que estes intervalos não decorrem somente das problemáticas de espaço e de organização do museu, mas sim das contingências inerentes à formação, incorporação e registro do conjunto dos objetos no museu que trespassam as relações materiais e imateriais entre objetos e sujeitos. Estas reformulações do objeto no trânsito para, e do museu, transmutam-se em dados distintos, muitas vezes simplificados e generalizados no momento da catalogação em função da praticidade e da inteligibilidade da informação. $O$ foco na relação entre objeto e sujeito na contemporaneidade permitiu identificar que a homogeneização da coleção etnográfica W. Lipkind num registro temporal uníssono omite o descompasso das partes I, II e III, resultado da formação de duas coleções em momentos distintos no ano de 1939, e que foram incorporadas ao MN entre 1939 e 1941, e registradas em 1939, 1941 e 1953. Os desafios da ativação das vozes e dos vínculos omitidos na sua documentação museológica através da sua recontextualização persistem no que se refere à reclamação das vozes daqueles, cujas coisas, se atrelaram originalmente aos objetos dos povos indígenas.

Concluímos igualmente que os procedimentos museológicos da coleção mostram a intrínseca relação da biografia dos objetos e a biografia das instituições e das pessoas, e da rede que se construiu em torno desta. Torna-se claro que as entradas da coleção, as saídas para exposições, os registros do livro de tombo em tempos diferenciados e a reforma de um prédio histórico sem correlacionar tais procedimentos com as tensões, propósitos, apoios e atos administrativos das instituições e de personas políticas nestas envolvidos, como a Universidade de Columbia, a Embaixada Norte-americana, o Conselho de Fiscalização das Expedições Artísticas e Científicas no Brasil, o Ministério da Educação e o Museu Nacional, além de William Lipkind, Franz Boas, Ruth Benedict, Charles Wagley e Heloísa A. Torres.

A circularidade das coisas e dos seus fluxos (Ingold 2012) entrelaça-se com a circularidade das pessoas e dos seus propósitos. Esta experiência de pesquisa e de escrita mostrou quão fecundo é o diálogo académico entre a Museologia, história e a antropologia, trazendo à tona historicidades e sentidos polissémicos dos espaços museológicos e das trajetórias profissionais trilhadas pelo saber-fazer dos antropólogos. Esse ato hermenêtico abre, assim, espaço para outras possibilidades de interação da coleção W. Lipkind como a dos indígenas nesta representados, possibilitando o exercício pleno de uma cidadania patrimonial e a ampliação e a multiplicação dos olhares com vista a aprimorar o potencial argumentativo e inclusivo das instituições museológicas (Bruno 2014). 


\section{BIBLIOGRAFIA}

“Pagé dos Javahés." 1939. o Globo, novembro 15. Edição matutina, seção geral, p. 4.

Almeida, Bernardo P. 1996. O Plano de Imagem: Espaço de Representação e Lugar do espectador. Lisboa: Assírio e Alvim.

Andrade, Rafael Santana Gonçalves de. 2016. “Os Huumari, o Obi e o Hyri: A Circulação dos Entes no Cosmo Karajá." Dissertação de mestrado em Antropologia Social. Universidade Federal de Goiás.

Appadurai, Arjun. 2008. A Vida Social das Coisas. Rio de Janeiro: EdUFF - Editora da Universidade Federal Fluminense.

Benedict, Ruth. 1938. "Ruth Bennedict, carta enviada a Honorable Caffery, 4 de junho de 1938." Dossiê William Lipkind. Fundo CFE.T.2.105. Museu de Astronomia e Ciências Afins (MAST). Material de arquivo.

Benedict, Ruth. 1939. "Draeger Shipping Co. INC., 12 de junho de 1939.” Ruth Fulton Benedict Papers. Folder 31.11. Special Collections. USA. Vassar College Archives. Material de arquivo.

Bottallo, Marilúcia. 1996. “A Gestão Documental do Patrimônio Arqueológico e Etnográfico.” Revista do Museu de Arqueologia e Etnologia 6: 287-292.

Brown, Bill. 2001. "Thing Theory.” Critical Inquiry 28 (1): 1-22.

Bruno, Maria Cristina Oliveira. 2014. "Processos Museológicos: Os Caminhos para a Gestão em Museus." In Fronteiras Regionais e Perspetivas Nacionais: Museologia, História, Moda, Sociologia, Educação e Turismo, Seminário interdisciplinar em Museologia, 100-105. Blumenau: Museu Hering: Fundação Herman Hering.

Canclini, Néstor García. 1997. Culturas Híbridas: Estratégias para Entrar e Sair da Modernidade. São Paulo: EDUSP - Editora da Universidade de São Paulo.

Castro Faria, Luiz de. 1949. As Exposições de Arqueologia e Antropologia do Museu Nacional. Publicações Avulsas do Museu Nacional, n.ำ 4. Rio de Janeiro: Departamento de Imprensa Nacional.

Corrêa, Marisa, e Januária Mello, eds. 2008. Querida Heloísa: Cartas de Campo para Heloísa Alberto Torres. São Paulo: Unicamp - Universidade Estadual de Campinas.

Corrêa, Marisa. 1997. “Dona Heloísa e a Pesquisa de Campo.” Revista de Antropologia 40 (1): 11-54.

Cunha, Olivia, e Celso Castro. 2005. “Quando o Campo é o Arquivo.” Estudos Históricos 36: 3-5.

De Waal, Edmund. 2012. A Lebre dos Olhos de Âmbar/The Hare with Amber Eyes. Rio de Janeiro: Editora Intrínseca.

Ewbank, Cecilia, e Maria Gripp. 2016. "O Oculto em Movimento: Ressignificando uma Coleção Etnográfica na Reserva Técnica.” Anais da 30. ${ }^{a}$ RBA.

Gonçalves, José Reginaldo Santos. 2007. Antropologia dos Objetos, Coleções e Patrimônios. Rio de Janeiro: IPHAN - Instituto do Patrimônio Histórico e Artístico Nacional. 
Groupioni, Luís Donisete Benzi. 1998. Coleções e Expedições Vigiadas: Os Etnólogos no Conselho de Fiscalização das Expedições Artísticas e Científicas do Brasil. São Paulo: Editora Hucitecx/Anpocs.

Ingold, Tim. 2012. "Trazendo as Coisas de Volta à Vida: Emaranhados Criativos num Mundo de Materiais." Horizontes Antropológicos 18 (37): 25-44.

Kopytoff, Igor. 2008. “A Biografia Cultural das Coisas: A Mercantilização como Processo.” In A Vida Social das Coisas, ed. Arjun Appadurai, 89-121. Rio de Janeiro: EdUFF - Editora da Universidade Federal Fluminense.

Lima Filho, Manuel Ferreira. 2010. “Espelhos Patrimoniais em Ouro Preto: Museus e Passado Afrobrasileiro.” Revista TOMO 16 (I): 197-220.

Lipkind, William. 1938. William Lipkind, carta enviada a Heloísa Alberto Torres, 24 de dezembro de 1938. Dossiê William Lipkind. Casa de Cultura Heloísa Alberto Torres. Material de arquivo.

Lipkind, William. 1939a. William Lipkind, carta enviada a Heloísa Alberto Torres, 2 de setembro de 1939. Dossiê William Lipkind. Casa de Cultura Heloísa Alberto Torres. Material de arquivo.

Lipkind, William. 1939b. "William Lipkind, carta enviada a Ruth Bennedict, 1 de maio de 1939." Ruth Fulton Bennedict Papers. Folder 31.11. Vassar College Archives. Material de arquivo.

Museu Nacional. 1939. "Relatório das atividades do Museu Nacional durante o mês de agosto de 1939.” Cópias de ofício (jul-set) 1939, RA 106, p. 148-150. Seção de Memória e Arquivo do Museu Nacional (SEMEAR/MN). Material de arquivo.

Museu Nacional. 2007. São Paulo: Banco Safra.

Nascimento, Fátima Regina. 2009. “A Formação da Coleção de Indústria Humana do Museu Nacional, século XIX.” Tese de Doutorado em Antropologia, Universidade Federal do Rio de Janeiro.

Pomian, Krystof. 1984. “Coleção.” In Enciclopédia Eunaudi, v. 1, 51-86. Lisboa: Imprensa Nacional da Moeda.

Price, Sally. 2007. Paris Primitive: Jacques Chirac Museum on the Quai Branly. Chicago: The University of Chicago Press.

Price, Sally. 2016. "Higienização da Cultura: Poder e Produção de Exposições Museológicas." In Museus e Atores Sociais: Perspetivas Antropológicas, ed. Manuel Lima Filho, Regina Abreu, e Renato Athias, 273-284. Recife: Editora UFPE - Editora Universitária.

Ribeiro, Berta Gleizer. 1988. Dicionário do Artesanato Indígena. Belo Horizonte: Itatiaia: EDUSP Editora da Universidade de São Paulo.

Rússio, Waldisa. 1990. “O Conceito de Cultura e sua Inter-relação com o Patrimônio Cultural e a Preservação.” Cadernos Museológicos (IBPC) 3:7-12.

São Paulo (Estado). Secretaria da Cultura. 2010. Documentação e Conservação de Acervos Museológicos: Diretrizes. São Paulo: ACAM Portinari.

Semedo, Alice. 2005. "Políticas de Gestão de Coleções (parte 1)." Revista da Faculdade de Letras, Ciências e Técnicas do Património I (IV): 305-322.

Silveira, Flávio L. Abreu da, e Manuel Ferreira Lima Filho. 2005. "Por uma Antropologia do Objeto Documental: Entre a 'a alma nas coisas' e a Coisificação do Objeto.” Horizonte Antropológicos 11 (23): 37-50.

Stocking, George W. 1992. The Ethnographer's Magic and other Essays in the History of Anthropology. Madison: Univ. of Wisconsin Press. 
Taveira, Edna Luísa de Melo. 1982. Etnografia da Cesta Karajá. Goiânia: Editora da Universidade Federal de Goiás.

Thomas, Nicholas. 1991. Entangled Objects. Exchange, Material Culture and Colonialism in the Pacific. USA: Harvard University Press.

Torres, Heloísa Alberto. 1938. "Heloísa Alberto Torres, ofício enviado a Gustavo Capanema, 25 de abril de 1938.” Cópias de ofício (abr-jun) 1938, RA 101, Ofício 195. Seção de Memória e Arquivo do Museu Nacional (SEMEAR/MN). Material de arquivo.

Torres, Heloísa Alberto. 1939. "Heloísa Alberto Torres, ofício enviado a Gustavo Capanema, 8 de março de 1939." Cópias de ofício (jan-mar) 1939, RA 104, Ofício 114, p. 161-162. Seção de Memória e Arquivo do Museu Nacional (SEMEAR/MN). Material de arquivo.

Torres, Heloísa Alberto. 1941. "Heloísa Alberto Torres, carta enviada a Franz Boas, 2 de janeiro de 1941." Franz Boas Papers. Mss.B.B61. American Philosophical Society. Consultado em 17 de julho de 2017. http://diglib.amphilsoc.org/islandora/object/text:123772\#page/1/mode/1up

Trouillot, Michel-Rolph. 1995. Silencing the Past: Power and the Production of History. Boston: Beacon Press.

Velthem, Lucia Hussak van. 2012. “O Objeto Etnográfico é Irredutível? Pistas sobre Novos Sentidos e Análises.” Boletim do Museu Paraense Emilio Goeldi 7 (1): 51-66.

Wagley, Charles. 1939. "Charles Wagley, carta enviada ao CFE, 8 de março de 1939.” Dossiê William Lipkind, CFE.T.2.100. Museu de Astronomia e Ciências Afins (MAST). Material de arquivo.

\section{NOTAS}

1. Projeto Kanaxywe e o mundo das coisas Karajá - Patrimônios, Museus e Estudo Etnográfico da Coleção William Lipkind do Museu Nacional, Rio de Janeiro. CNPq.

2. Esta etapa inicial serviu de base para o desenvolvimento de outras etapas, cujo objetivo final consistiu na devolução simbólica da coleção e do seu uso patrimonial e educacional aos Karajá a partir de uma visita à reserva técnica, ativando o potencial dialógico do museu.

3. Grupo indígena que habita a bacia do Rio Araguaia, na região central do Brasil e que se dividem em três subgrupos: Karajá, Javaé e Xambioá ou Karajá do Norte.

4. Relação que se estabelece entre o sujeito e o objeto no cenário do museu, segundo Rússio (1990, 9).

5. A coleção etnográfica W. Lipkind foi alvo de pouca atenção antropológica. Apenas Grupioni (1998) e Taveira (1982) lhe fazem referência. No âmbito museológico, Ribeiro (1988) baseou-se em alguns itens da coleção para elaborar as categorias tipológicas do Dicionário do Artesanato Indígena. 6. A coleção de etnologia do MN possui 21 Livros de Registro, com o registro de entrada do acervo no que atualmente são as Seções de Arqueologia, Etnologia e Antropologia Biológica (Nascimento $2009,41)$.

7. Agradecemos à funcionária do SEE/MN, Michelle Barcellos, pela verificação da data e coleção correspondente dos itens registrados imediatamente antes das três partes da coleção W. Lipkind.

8. W. Lipkind tinha um acordo informal estabelecido entre Franz Boas e Ruth Bennedict, da Universidade de Columbia, e entre Heloísa Alberto Torres, do Museu Nacional, objetivando a realização de pesquisas de campo e a formação de etnólogos no Brasil. Nesse âmbito viriam também os antropólogos Buell Quain, Charles Wagley e Ruth Landes, e depois James e Virginia Watson, e Yolanda e Robert Murphy (Corrêa 1997). 
9. Texto traduzido para português pelos autores. No original: «I should like to hear from the American Museum before I begin collecting again» (Lipkind 1938, s/p). A referência é ao Museu Americano de História Natural.

10. Dossiê William Lipkind, CFE.T.2.105. Museu de Astronomia e Ciências Afins (MAST).

11. A parte da coleção enviada para os Estados Unidos encontra-se dividida entre a Smithsonian Institution (cilindros de cera, negativos em vidro, cadernos de campo e correspondência), o Arquivo de Música Tradicional da Universidade de Indiana (cilindro de cera gravado em 1938, contendo músicas, lamentos, e onomatopéias Karajá e Caiapó) e coleções particulares. Informações retiradas de: http://anthropology.si.edu/naa/guide/_l2.htm (consultado em março 17, 2017)

12. Referente aos itens registrados sucessivamente entre os números 28.611 e 28.752 .

13. A diretora também acusa o recebimento de fotografias documentando aspetos da vida dos índios Trumai, do Xingu, por parte de Buell Quain (Torres 1939).

14. Algumas são objetos compósitos representando famílias ou casais.

15. Compreende-se por Karajá os registros identificados como Karajá, Karajá de baixo e Karajá do Grisote.

16. Compõem ainda a coleção três itens Caiapó e um Tapirapé, além de 63 itens sem identificação.

17. Didemas, coifas, coroas e capacetes.

18. Texto traduzido para português pelos autores. No original: «I'am bringing a Carajá companion with me to Rio. The dance-masks had to be taken apart to be packed, and he'll assemble them in the museum. If you can arrange our passage on the Lloyd Brasileiro or Costeira, it would be helpful» (Lipkind 1939a, s/p).

19. Texto traduzido para português pelos autores. No original: «I don't know how it will be for you to raise eight hundred dollars [...]. Perhaps you can get some of it on the collection Dona Heloisa has sent you" (Lipkind 1939b, s/p).

20. Texto traduzido para português pelos autores. No original: «My present collections ought to help more. I have much better looking stuff, feather hats, masks, crystal chin plugs. I have sixteen in perfect condition of the chin plugs and a collector in São Paulo offered me a conto a piece for all I could find. Perhaps they'll bring more in New York. They're very rare and beautiful. They're as well made as the finest West Indians celts and the stone is much nicer, a white shining stone, quartz, I think. I got so many by pure luck. I dug up an ancient cemetery and found them. Even after Dona Heloisa does her worst enough will be left to make up part of the Money» (Lipkind 1939b, s/p).

21. O emprego da marcação do número de registro nos tembetás também difere entre os conjuntos das classes 30 e 36 mil. Enquanto a marcação dos tembetás registrados na classe dos 30 mil foi realizada com uma camada de verniz incolor, a camada utilizada para aqueles registrados na classe dos 36 mil apresenta uma coloração opaco e amarelada, sugerindo uma reação na mistura empregada e diferentes tempos de catalogação.

22. As etapas de localização, identificação, registro fotográfico, catalogação e acondicionamento foram realizadas pelas museólogas Cecilia de Oliveira Ewbank e Maria Piero Gripp (ver Ewbank e Gripp 2016).

23. Data correspondente à coleta/registro do item 30.683 cuja catalogação precede a do primeiro objeto coletado por W. Lipkind na classe dos 30 mil (30.684).

24. Texto traduzido para português pelos autores. No original: «I must tell you that I helped Dr. Lipkind as much as I could, more than ever done to any of the anthropologists form Columbia who have been in Brazil; due to financial circumstances of the moment I could help him even in this respect. It is true that he left a beautiful ethnographical collection of the Karajás to this Museum. A different attitude on his part as regards other grounds would have been expected. I am sorry to state that this own private collection may be confiscated for lack of fulfillment of the 
legal requisites mentioned above. I have postponed this decision up to now but do not believe the situation can be made to last any longer» (Torres 1941, s/p).

25. Como indica o registro da sandália coletada por Heloísa A. Torres, na excursão que realizou nesse ano à Cachoeira, na Bahia, sob o número imediatamente anterior ao início da catalogação da parte III da coleção, no Livro de Registro n.o 19.

\section{RESUMOS}

O presente texto visa contribuir para a reflexão sobre os silenciamentos das características biográficas de coleções etnográficas musealizadas, especialmente no que se refere ao contexto da sua aquisição, através da análise do inventário de uma coleção Karajá no Museu Nacional do Rio de Janeiro (MN). Trata-se da coleção reunida pelo antropólogo norte-americano William Lipkind (1904-1974), aquando da sua vinda ao Brasil para realizar uma pesquisa de campo na região do Araguaia, em Goiás, entre 1938 e 1939, e incorporada no MN como parte da política nacional de fiscalização das expedições científicas no país. O questionamento acerca do registro da coleção etnográfica W. Lipkind no MN permitiu inferir sobre tempos distintos de aquisição e de incorporação, colocando em evidência os desafios de compreender esta coleção através da relação entre sujeito e objeto. Mais do que no registro do acervo, a análise da configuração da coleção teve lugar nos documentos de arquivo que salvaguardam a memória dos vínculos de identidade mantidos pelos objetos com as personagens que delineiam a sua narrativa.

The present paper aims to contribute to the reflection on the current silencing of the biographical characteristics of ethnographic collections exhibited in museums, especially with regard to the context of their acquisition, through the analysis of the inventory of a Karajá collection at the National Museum (NM) of Rio de Janeiro. This is the collection collected by the north-American anthropologist William Lipkind (1904-1974) when he came to Brazil to carry out field research in the Araguaia region of Goiás, between 1938 and 1939, and which was incorporated into the NM as part of the national policy of inspection of scientific expeditions in the country. The questioning about the recording of the W. Lipkind ethnographic collection in NM allowed us to infer about different times of acquisition and incorporation, highlighting the challenges of understanding the collection through the relation between subject and object. More than in collection inventories, the analysis of the configuration of the collection took place in archival documents that safeguard the memory of the identity bonds maintained by the objects with the characters that outline their narrative.

\section{ÍNDICE}

Palavras-chave: coleção William Lipkind, Museu Nacional do Rio de Janeiro, Heloísa Alberto Torres, biografia de objeto, coleção etnográfica, Karajá

Keywords: William Lipkind collection, National Museum of Rio de Janeiro, Heloísa Alberto Torres, object biography, ethnographic collection 


\section{AUTORES}

\section{CECILIA DE OLIVEIRA EWBANK}

Museóloga. Bacharel em Museologia pela Universidade Federal do Estado do Rio de Janeiro (UNIRIO). Mestranda do programa de pós-graduação em História Social da Universidade Federal de Santa Catarina (UFSC). Membro do METROPOLIS - Laboratório de Pesquisa Social (Ciências Sociais - UFSC). Tem experiência na área de Museologia, em particular na área da conservação, catalogação e organização de coleções etnográficas e de arte contemporânea.

Programa de pós-graduação em História Global, Departamento de História, Centro de Filosofia e Ciências Humanas da Universidade Federal de Santa Catarina, Trindade, 88040-970 Florianópolis - Santa Catarina, Brasil, oe.cecilia@gmail.com

\section{MANUEL FERREIRA LIMA FILHO}

Antropólogo. Doutor em Antropologia Social pela Universidade de Brasília. Professor associado DE na Faculdade de Ciências Sociais e no Museu Antropológico da Universidade Federal de Goiás (UFG), e pesquisador do CNPq, 2. Conselheiro da Associação Brasileira de Antropologia. É docente no programa de pós-graduação em Antropologia Social e no programa de pós-graduação em Sociologia da Universidade Federal de Goiás. É membro do NEAP - Núcleo de Estudos de Antropologia, Patrimônio, Memória e Expressões Museais da UFG. Tem experiência na área de antropologia, com ênfase em património cultural, memória social, cultura material e etnologia indígena, atuando principalmente nos seguintes temas: património cultural, cidade, memória coletiva, identidade social e Karajá.

Faculdade de Ciências Sociais da Universidade Federal de Goiás, Campus II, caixa postal 131, 74.001-970 Goiânia - Goiás, Brasil, manuellimafilho@gmail.com 